\title{
Revision in Iris Murdoch's Under the Net
}

\author{
B I L L I E B A T CHELOR
}

An examination of a holograph manuscript of Under the Net and a comparison of it with the Viking Press first edition (1954) indicate that there were two revisions, each guided by different principles, in the text of Iris Murdoch's first novel. The first revision was of the manuscript itself-a series of deletions, additions, and revisions. The second revision occurred some time between the revision of the manuscript $^{1}$ and the first printing. The changes in this second revision are so extensive as to suggest the possibility of another manuscript intervening between the Iowa manuscript and the text as first printed by Viking Press.

The Iowa manuscript consists of seven notebooks. On the recto of leaf one of each notebook there is a designation of the order of the notebooks (e.g., Book I, Book II, etc.) and a date written by Miss Murdoch. These dates probably indicate the date that composition began for each of these portions of the manuscript; i.e., Book I, July 18, 1952; Book II, July 29, 1952; Book III, September 29, 1952; Book IV, October 2, 1952; Book V, October 25, 1952; Book VI, March 16, 1953; and Book VII, March 27, 1953. On the last page of the manuscript (Book VII, page 29), with lines drawn through them, are two dates-November 21 and March 28.

The text of the manuscript begins on the recto of leaf two of each notebook and is continued on the recto of each leaf throughout the notebooks. There is pagination in pencil of Book I and part of Book II. Pagination is not continued through the notebooks. There are, however, ninety-seven pages in Book I, fifty-nine in Book II, fifty-nine in Book III, fifty-nine in Book IV, fifty-seven in Book V, fifty-nine in Book VI, and twenty-nine in Book VII, a total of 419. The verso of each leaf is

1 The holograph manuscript owned by The University of Iowa Library, hereafter referred to as the "Iowa manuscript." 
blank except for notes concerning possible revisions, alternate readings, and, in some cases, passages to be inserted in the text.

There are three distinct stages in the development of this novel. The first is the writing of the complete novel, the second is the first revision, and the third the second revision. The writing of the manuscript seems to have proceeded rapidly. There is no evidence of hesitation or uncertainty in the general progress of the story. The highly evocative descriptions of Paris and London are remarkably free from correction or revision.

It is possible to distinguish between the initial composition and the first revision because in the former rejected readings are crossed out and are followed immediately by their replacements. Alternate readings are written on the verso of the leaf. In the first revision, which probably occurred after the first draft of the manuscript was completed, the revisions are written interlinearly or on the verso of the leaf in ink of darker blue than that of the adjacent text.

There were only two long changes during the initial composition in which substantial portions of the original manuscript were rewritten. The first was rewriting of a full three pages of manuscript (Viking Press edition, pp. 78-81), the section in which Sammy is placing bets for Jake. In the rejected passage, the speech of Sammy has not been clearly distinguished from that of Jake and the excitement of the situation is not clearly conveyed. It is a dull, colorless passage. But in rewriting it Miss Murdoch achieved a nervousness and excitement, and Sammy's speech is clearly distinguished from that of Jake. Miss Murdoch incorporated words and phrases of gamblers' cant to achieve Sammy's vigorous idiom in this lively interchange. She also tinkered with the passage during the first revision. For example, Sammy's "I'll 'phone one of my friends at the course and we'll get the best price there is" has been revised to read "Hold onto your hat, my boy, while I just get the office on the blower."

The other substantial change during initial composition was the deletion of a full page from the manuscript (Viking edition, p. 149, following "That wasn't too bad"). The deleted section is concerned with plotting rather than with characterization. Jake telephones Sammy and tells him about having Mars and the possibility of exchanging Mars for the typescript of the Wooden Nightingale. The deletion of this passage of dialogue indicates a change in the plotting of incident. It is, of course, impossible to know what arrangement of incident might have followed this disclosure. Rather than telephoning Sammy as in the marked out passage, Jake tries to telephone Hugo, is unable 
to reach him and so decides to go to the studio. In the following chapter Jake goes to the studio and finds Hugo listening so attentively to Lefty's harangue that it is only possible to gain his attention by separating him from the audience by the use of a judo throw. The arrival of the United Nationalists and the police prevents a discussion between Jake and Hugo, and Jake only escapes by commanding Mars to feign "dead." This entire chapter of the Belfounder studio episode intervenes before the chapter in which Jake and Dave discuss the matter of Mars, and Dave tells Jake that he (Dave) and Finn telephoned Sammy and told him about Jake's possession of the dog. This change in plotting makes possible the subsequent negotiations with Sadie.

In addition to these two rewritten passages, Miss Murdoch changed the name of the major character from Malone to Donaghue during initial composition. The name Malone is used in Book I, page 28, and Book II, pages 15, 27, 39, and 58. The first instance of the use of the name Donaghue occurs in Book III, page 33 (Viking edition, p. 126). The earlier uses of Malone have been corrected with "Donaghue" written interlinearly and all uses of the name following Book III, page 33, are clearly Donaghue with no substitutions. This would indicate that between September 29, 1952 (the beginning of Book III) and October 2, 1952 (the beginning of Book IV), she altered the name of her major figure. This change is perhaps related to the matter of influences. Miss Murdoch has stated: 'Jake's ancestors are Beckett's Murphy and Queneau's Pierrot," 2 and one of the two books mentioned by name when Madge returns them to Jake is Murphy. ${ }^{3}$ The acknowledged influence of Beckett and the use of this title in the text suggest that the selection of the name Malone was probably a conscious choice related to Beckett's practice of using names beginning with " $M$," and that the name Donaghue was substituted after the appearance in England of Beckett's Malone meurt (Paris, Editions Minuit, 1951).

Most deletions during the first revision were so heavy as to make the cancelled matter illegible. But enough of the cancellations are still legible to indicate the purposes of this revision. Miss Murdoch was seeking clarity and precision of style. Other than those just cited in the initial composition there are no changes in the structure of the novel, the progress of the story or in the larger aspects of character, scene, and action. The revisions are all related to style, the desire to secure as rich a texture for the novel as possible. Alternate readings

2 William Van O'Connor, The New University Wits (Carbondale, 1963), p. 54 .

3 Samuel Beckett, Murphy (London, 1938). 
written on the verso of the leaf are at this point rejected or incorporated into the text.

There were many revisions, additions, and deletions at this stage. Examples can be found throughout the manuscript. On the first page, for instance, there is the addition of "at once" in the line "When I saw Finn waiting for me at the corner of the street I knew at once that something had gone wrong." "Return" has been changed to "journey back" and "anyway" has been added in the line "I hate the journey back to England anyway. ..." The word "dear" has been added in the phrase "in dear London," and the word "utterly" in ". . . I was utterly abandoned. . .." Two lines, "with nothing to place between me and a sunless vista of my past present and future," have been deleted following "On this occasion too the bottles of cognac which I always smuggle had been taken from me by the Customs, so that when the pubs closed I was utterly abandoned to the torments of a morbid self-scrutiny." The final line of the first paragraph has been changed from "So all things considered, it was odd that ..." to "So all this being considered, it was an odd thing that ..." Another revision (Viking edition, p. 5), this one a change from a learned allusion to an effective, original image, is as follows: "I would be at pains to set my poor universe in order and have it ticking like a clock when suddenly the old incorrigible chaos would break loose again. . .." becomes "I would be at pains to put my universe in order and set it ticking, when suddenly it would burst again into a mess of the same poor pieces. ..." And "Magdalen emerged from the bathroom ..." becomes "Magdalen swept out of the bathroom..." (Viking edition, p. 8).

The second revision, that between the completion of the revised holograph manuscript and the first printing, was guided primarily by a motive of economy. A comparison of the revised manuscript with the printed text indicates that some changes were like those of the first revision, but in this phase Miss Murdoch was concerned mainly to tighten her prose through the elimination of extensive passages. There are eighty-seven deletions, varying in length from a single sentence to quite long passages. There are three massive deletions. The first (See Viking edition, p. 61) consists of two parts-one, an elaboration of the subject matter of the discussions between Jake and Hugo; the second, an explicit statement concerning Hugo's thought. The second part of this deletion following “. . . and after a while my passion became to discuss with Hugo not so much politics or art or sex, but what it was that was so peculiar in Hugo's approach to politics or art or sex." is:

Yet to get this clear seemed very nearly impossible since Hugo held 
no general views and was incapable of a discussion that was carried or in general terms. There seemed indeed something contradictory in expecting Hugo to give a general account of his attitude since his attitude was a continual denial of the possibility of general accounts. Hugo was a phenomenon which demanded to be investigated by his own methods, but these methods could not but fail to produce the kind of explanation I was after. Again and again I would try to force him or trap him into making some summary statement of his position, and again and again he would fail to reply or else would offer me some particular and concrete remark which was not at all what I wanted. I said to him once: "So you think that any general theory is necessarily false? That only statements about individual things can be true?" To which Hugo, after an enormously long silence and much biting of his knuckles, replied: "What can you mean here? I don't know anything about general theories. They all seem so different. I suppose a scientist would know what it means to say that the law of gravitation was true, while all I know is that things fall to the ground. But why should I want to say anything about what the scientist would say, except that I don't know what it is, and probably wouldn't understand it if I did?" I nearly gave up in despair.

And following "At last we did have a conversation that seemed to me to touch on something central to Hugo's thought."

if Hugo's thought could be said at all to have anything so figurative as a centre. He himself would probably have denied this; or rather, I'm not sure that he would have known what it meant for his thoughts to have an orientation.

And following "From Proust we were led on to discuss what it meant to describe a feeling or a state of mind. Hugo found this very puzzling,"

as indeed he found everything puzzling.

While these two pages of manuscript material are not irrelevant or digressive, such a full explication of Hugo's thought would certainly diminish the credibility of the peripeteia, when Jake finally realizes that the ideas in The Silencer are his own (Viking edition, p. 240).

The two other massive deletions amounted to four full pages of manuscript (at Viking edition, pp. 107 and 108). Both passages are dialogue between Jake and Lefty concerning the nature of English socialism. A part of the deleted dialogue is as follows:

"All right," I said, "it's this. English socialism is perfectly worthy, but it's not socialism. It's welfare capitalism. It doesn't touch the real curse of capitalism, which is that work is deadly. And continental socialism is communism."

"... Are we all Marxists here?"

"Oh, Marxists, yes!" I said. 
"I mean are we agreed capitalism is on the way out?"

"It's on the way out."

"Mind you," said Lefty, "we don't yet know what this means. But so far so good. We think Marx is right-yet we can't be communists. We'd like to be communists, wouldn't we?" he asked, thrusting his glass against my chest. I agreed that maybe we would. "But we can't be. We're too bourgeois. Rotten with bourgeois ideas about the integrity of the individual, what? Shall we say that?"

I said I didn't mind.

"We can't take it," said Lefty, "and God knows if we're right, but that's where we stand, and we can't stand anywhere else. Good. Now tell me this. Why has England never developed a socialist foreign policy?

"Because to make socialism as comfortable as imperialism we sold ourselves into economic slavery."

An inclusion of these four pages would have resulted in an undue emphasis on the political question. They are set pieces which are, as Jake suggests in the deleted section, "like a catechism." In the novel Lefty is the "manipulator of words," a mass-age man whose eloquence has made it possible for him to usurp the function of poet-prophet. The theme of Under the Net is the place of the artist in a world in which the masses have become articulate and the most eloquent of them are assuming the power once possessed by the artist. Jake, the artist, is reduced to silence. Lefty's function in the novel is to represent the political orator, one of the mass-age "manipulators of words," 4 and this function is not fully realized in these four pages of rather didactic dialogue. The concept is much better embodied in the later scene at the studio in which Lefty, using his power of words, mesmerizes the masses. The question is not whether Lefty's political views are tenable, but whether his power ("the power of the word") is misplaced.

Also eliminated are four rather long passages, totaling about two pages of manuscript, which are concerned with the physical features of the hospital, procedures there, a comment on the relationship between nurses and sisters, and a section about the patients. These are passages of realistic detail that have been eliminated because they are needless amplifications of the phenomena of daily life at the hospital.

A short deletion in this last stage of revision occurs at the end of the

${ }^{4}$ For a full discussion of the use of language by these "manipulators" of words, and the antithesis, silence, and the use of these themes in contemporary literature, including Under the Net, see Benjamin De Mott, "Dirty Words?" Hudson Review, XVIII, no. 1 (Spring, 1965), pp. 31-44. 
novel. The concluding line of the Viking text is: "I don't know why it is," I said. "It's just one of the wonders of the world." The manuscript continues:

I prepared to leave the shop. I wanted to see the odd looking man who lived near Hampstead Heath and did not believe in petty restrictions. "I shall walk," I told Mrs. Tinckham, "it's such a beautiful evening and Mars needs exercise." "Well, don't forget to come back if you need a bed," said Mrs. Tinckham. "Your things will be safe here." She began to stow them under the counter. "So long," I said. "So long," said Mrs. Tinckham. I left the shop with Mars. The sun was shining and a warm air was blowing through Soho. A blue sky arched over London. Mars capered about me and then bounded ahead. I turned into Tottenham Court Road.

\section{The End}

It is appropriate that a novel concerned with an artist's creative powers should conclude with a playful discussion of fecundity. The continuation in the manuscript blurs the effect and diminishes the significance of the preceding dialogue.

The result of these revisions was twofold: on the one hand, added compression, economy and concentration, and on the other hand, richness and density of texture and an overall stylistic excellence. As a result, too, Under the Net acquired favorable reviews, a continuing critical attention, and a general popularity attested by translation and publication in Italy (1956), Sweden (1956), France (1957), Switzerland (1957), Germany (1962), and Spain (1962). 
"Little Gronge will win the three o'dock at Salibury soid Spuny. "A ceot, hut odds ou. Fe W'II fily

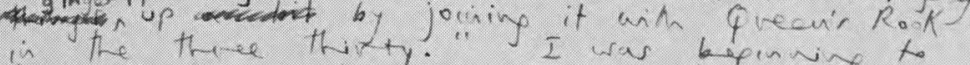

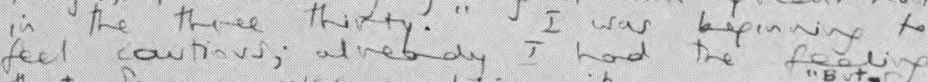

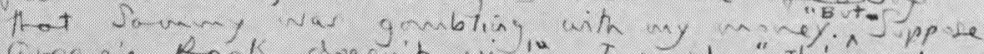
quecur, Rook cherit wim!" I J J, "It; not

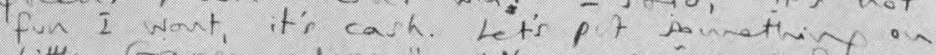

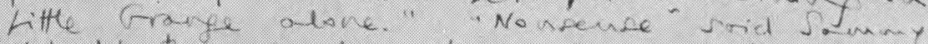

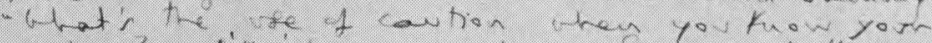

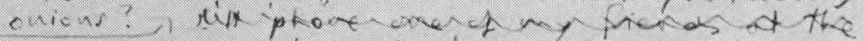

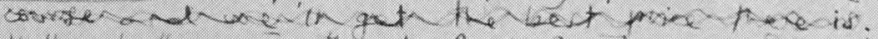
Hello, tello. IJ thont Andy? This is Jom."

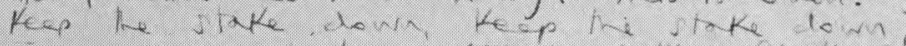

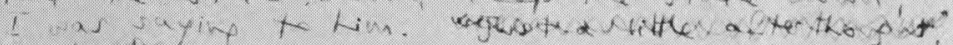

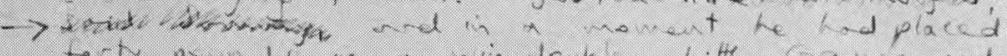

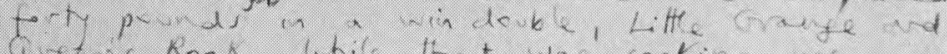
Gotar Kook. While that was cooking are

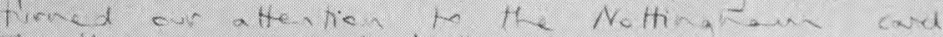

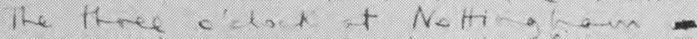

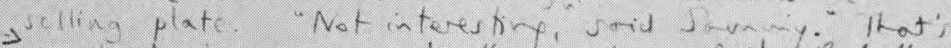

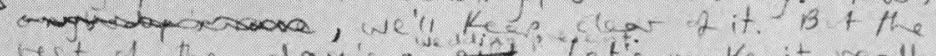

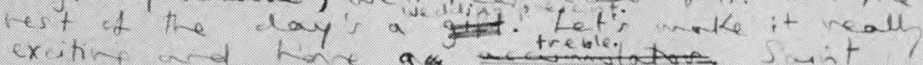

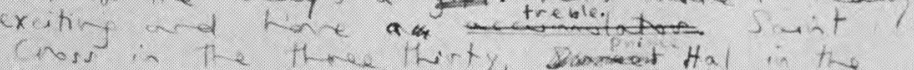

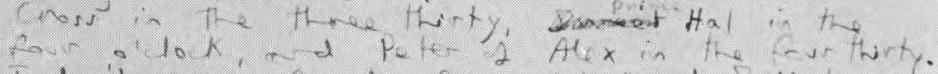
I dont care for he farm odode at Jalisbury.

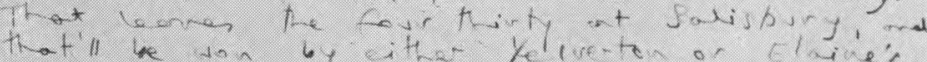

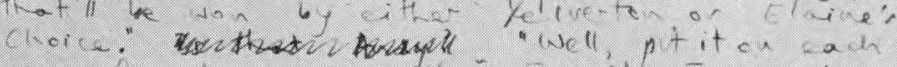
way, ro thenrea, S Ke;, joid. I poured

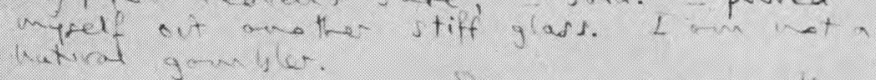

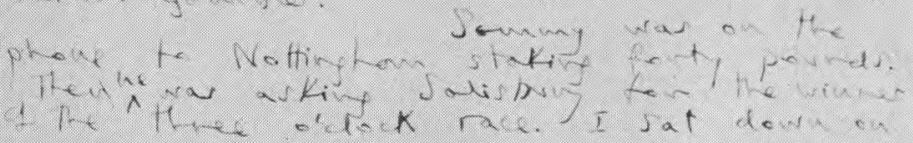

A manuscript page from Notebook 2 of Iris Murdoch's novel Under the Net. 